Instructions for authors, subscriptions and further details:

http://ijep.hipatiapress.com

\title{
Reviewing the Role of Cognitive Load, Expertise Level, Motivation, and Unconscious Processing in Working Memory Performance
}

Seffetullah Kuldas ${ }^{1}$, Shahabuddin Hashim ${ }^{1}$, Hairul Nizam Ismail ${ }^{1}$, Zainudin Abu Bakar²

1) Universiti Sains Malaysia, Malaysia

2) Universiti Teknologi Malaysia, Malaysia

Date of publication: June $24^{\text {th }}, 2015$

Edition period: June 2015 - October 2015

To cite this article: Kuldas, S., Hashim, S., Ismail, H.N., Bakar, Z. A. (2015). Reviewing the Role of Cognitive Load, Expertise Level, Motivation, and Unconscious Processing in Working Memory Performance. International Journal of Educational Psychology,4(2), 142-169. doi:

10.17583/ijep.2015.832

To link this article: http://dx.doi.org/10.17583/ijep.2015.832

\section{PLEASE SCROLL DOWN FOR ARTICLE}

The terms and conditions of use are related to the Open Journal System and to Creative Commons Attribution License (CC-BY). 


\section{Reviewing the Role of Cognitive Load, Expertise Level, Motivation, and Unconscious Processing in Working Memory Performance}

Seffetullah Kuldas, Shahabuddin Hashim, and Hairul Nizam Ismail Universiti Sains Malaysia
Zainudin Abu Bakar

Universiti Teknologi Malaysia

\section{Abstract}

Human cognitive capacity is unavailable for conscious processing of every amount of instructional messages. Aligning an instructional design with learner expertise level would allow better use of available working memory capacity in a cognitive learning task. Motivating students to learn consciously is also an essential determinant of the capacity usage. However, motivational factors are often subject to unconscious rather than conscious emotional processing. This review sets out the need for further studies to elucidate the role of motivation and unconscious processing in the use of cognitive capacity.

Keywords: cognitive effort, schema construction, expertise level, motivation, unconscious processing. 


\section{Revisando el Papel de la Carga Cognitiva, el Nivel de Dominio, la Motivación y el Procesamiento Inconsciente en el Rendimiento de la Memoria de Trabajo}

Seffetullah Kuldas, Shahabuddin

Hashim, and Hairul Nizam Ismail

Universiti Sains Malaysia
Zainudin Abu Bakar

Universiti Teknologi Malaysia

\section{Resumen}

La capacidad cognitiva humana no está disponible para el procesamiento consciente de cada cantidad de mensajes instructivos. La alineación de un diseño instruccional con el nivel de experiencia del principiante permitiría un mejor uso de la capacidad disponible de la memoria de trabajo en una tarea de aprendizaje cognitivo. Motivar a los estudiantes a aprender conscientemente es también una esencia determinante del uso de tal capacidad. Sin embargo, los factores de la motivación son a menudo objeto de procesamiento emocional inconsciente más que consciente. Este análisis expone la necesidad de realizar más estudios para dilucidar el papel de la motivación y el procesamiento inconsciente en el uso de la capacidad cognitiva.

Palabras clave: esfuerzo cognitivo, esquema de construcción, nivel de experiencia, motivación, procesamiento inconscient 


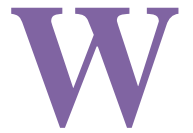

orking memory allows for active combinations of storage and manipulations of verbal and visual elements of information (Baddeley, 2012). However, its capacity and duration for these activities are limited, processing two to four chunks of novel information for no more than a few seconds (Cowan, 2001). The limitations of working memory are essential determinants of human (conscious) learning.

To optimise working memory performance (i.e., neither over- nor underloading the capacity for a coherent integration of novel and stored information) "Cognitive Load Theory (CLT)" has been widely applied to instructional manipulations (Sweller, Van Merriënboer, \& Paas, 1998). The theory chiefly suggests aligning an instructional design with relatively lower or higher level of learner expertise (Sweller, Ayres, \& Kalyuga, 2011). According to researchers (Kalyuga, 2011; Moreno, 2010; Paas, Tuovinen, Van Merriënboer, \& Darabi, 2005; Schnotz, 2010; Van Merriënboer \& Sweller, 2005), this alignment should also include motivational factors to explain how learners exert the necessary cognitive effort (i.e., the amount of cognitive capacity that learners devote to processing additional information germane to learning). However, an optimal alignment of an instructional design with levels of learners' expertise and motivation needs further clarification on at least two questions: Does the investment of more cognitive effort require high motivation? If it does so, is high motivation still conducive to learning when available cognitive capacity is low?

CLT has met with a rather different criticism from Schnotz and Kürschner (2007) regarding its account of conscious learning. They argued that learning takes place not only consciously, but also unconsciously, and not in working memory, but in long-term memory. Furthermore, working memory does not necessarily lead to the storage or reformation of knowledge in long-term memory. Unless the change happens, human learning does not occur. Evidence further suggests that neither a permanent nor temporary change in human memory can occur without unconscious processing (Kuldas, Ismail, Hashim, \& Bakar, 2013). Therefore, to restrict human learning to conscious processing prevents seeing the facilitatory or inhibitory role of unconscious processing in the allocation of cognitive effort (Kuldas, Hashim, Ismail, Samsudin, \& Bakar, 2014). To what extent 
unconscious processing affects the use of working memory is the other issue that merits further attention.

Accordingly, research within the framework of CLT is expected to be comprehensive by addressing to at least another two issues: how learner motivation is related to the use of working memory and how unconscious processing facilitates or inhibits working memory performance. On one hand, pursuing the main goal of how to optimise cognitive load, the research has mostly neglected an equally important goal of how to motivate learners to use the available cognitive capacity (Kuldas, Satyen, Ismail, \& Hashim, 2014). The literature shows that even if cognitive capacity is available, learners would exert little or no cognitive effort necessary for better learning when they lack motivation. On the other hand, focusing more on conscious processing, the research has also left largely unclear the role of unconscious processing. Learning and task performance can be facilitated by unconsciously constructed and automated knowledge, referred to as unconscious learning, mostly inaccessible to conscious awareness and control (deliberate and controlled attention) and thus verbally unreportable (Kuldas et al., 2013).

This narrative review presents a critical discussion about some boundaries of CLT and explains reasons for conducting further studies on the relation of motivation and unconscious processing with the use of working memory. Taking this relation into account, CLT would provide a new insight into the issue of how to use working memory better. The review falls under three main headings whereby respectively covers the three issues: (a) how cognitive load can be controlled or manipulated, (b) how the optimisation of cognitive load or learners' working memory performance is facilitated or inhibited by unconscious learning processes, including affects and motives; and (d) how learners can be stimulated to consciously exert more cognitive effort for better learning.

\section{Optimising Learners' Working Memory Performance: Cognitive Load Theory}

Better learning as the storage of knowledge structures in long-term memory (i.e., the construction of schemata - cognitive templates that enable learners 


\section{Kuldas et al - The Use of Working Memory}

to classify multiple elements of information into a single element according to their applications), requires an optimal use of working memory, which is central to CLT (Sweller et al., 2011). The theory aims "to provide guidelines intended to assist in the presentation of information in a manner that encourages learner activities that optimise intellectual performance" (Sweller et al., 1998, p. 25). CLT concerns instructional control over the interaction between the design of verbal (spoken or written text) and visual materials (animations, figures, or diagrams), the structure of cognitive learning tasks, and learners' cognitive characteristics. It focuses on the development of instructional methods that require less training time and less cognitive effort to attain durable and transferable learning outcomes.

According to CLT, the visual and verbal elements of information are essential cognitive loads on working memory. Cognitive load was traditionally described as consisting of three separate and additive loads intrinsic, extraneous, and germane. As De Jong (2010) suggested "one might say that intrinsic and extraneous cognitive load concern cognitive activities that must unavoidably be performed, so they fall under cognitive load; germane cognitive load is the space that is left over that the learner can decide how to use, so this can be labelled as cognitive effort" (p.113).

\section{Intrinsic Cognitive Load (ICL)}

ICL stems from learning tasks that are intrinsically difficult or complex. Learning a subject via a large number of verbal and visual elements that are highly interacting with one another is more difficult than learning a small number of the elements having lower interaction. The interactivity is low when a single element is learned in isolation (e.g., learning individual words independently of each other), but it is high when the element is learned in relation to other elements simultaneously, such as learning concepts or procedures (Pollock, Chandler, \& Sweller, 2002). ICL also depends on the characteristics of information (e.g., abstract and concrete levels of concepts); therefore, learning some information can intrinsically be more difficult than others, despite having the same level of interactivity and the same numbers of elements (Chi, 2005). 


\section{IJEP - International Journal of Educational Psychology 4(2) 147}

Whether or not ICL could be manipulated by an instructional design was a controversial issue; it was regarded as the fixed nature of a learning task that could not be altered at all (Paas, Renkl, \& Sweller, 2003) or directly (Sweller et al., 1998). On the contrary, Van Merriënboer, Kirschner, and Kester (2003) argued that ICL is controllable; a way of the manipulation is to sequence the interacting elements in a simple-to-complex order, preventing learners from experiencing the full complexity of the interaction at the outset. A similar way to reduce ICL is to isolate highly interacting elements (i.e., isolated-interacting elements effect) in a task. Pollock et al. (2002) suggested providing learners with individual elements, instead of initially presenting with full interaction between the elements. Once the individual elements are learned, learners can thereafter learn the full interaction. Thus, learners initially learn what individual elements are, and subsequently, learn how all the elements interact.

Another way to decrease ICL, as suggested by Gerjets, Scheiter, and Catrambone (2006), is to present learners with (a) molar worked-out examples (i.e., directing their attention to problem categories and category-specific solution procedures to learn), and (b) efficient modular worked-out examples (i.e., directing their attention to an individual problem category and its modular solution steps to learn). Both the simple-to-complex approach, starting with a few interacting elements (isolating highly interacting elements at the outset) and part-whole sequencing, starting with simple content that builds up complexity gradually, effectively decrease ICL (Van Merriënboer, Kester, \& Paas, 2006). However, instructional interventions to manipulate ICL can lead to unnecessary use of the available cognitive capacity, leading to “extraneous cognitive load" (Van Merriënboer \& Sweller, 2005).

\section{Extraneous Cognitive Load (ECL)}

An instructional design imposes ECL when it gives rise to modality, redundancy, and split-attention effects (Kalyuga, 2012). Simultaneous delivery of various textual and pictorial information through only the visual channel of working memory results in the modality effect. As for simultaneous reception of the same information via separate channels (auditory and visual modalities), the redundancy effect occurs (e.g., textual descriptions for a diagram that is intelligible in isolation). If a diagram is 


\section{Kuldas et al - The Use of Working Memory}

unintelligible and spatially segregated from textual description, learners would pay attention to the description while searching for its corresponding part on the diagram, and thus, the split-attention effect takes place. Moreno and Mayer (2007) suggested (a) presenting the information codes over audio-visual channel to avoid the modality effect; (b) excluding unnecessary information to eliminate the redundancy effect; and (c) synchronising the audio-visual information in time and space to control the split-attention effect.

In developing an instructional design, ICL and ECL are taken into account to prevent the design from imposing an inimical load on working memory. However, an equally important goal is to free up cognitive capacity for processing information relevant to schema construction, concerning the generation of germane cognitive load (Van Merriënboer et al., 2006).

\section{Germane Cognitive Load (GCL)}

GCL is associated with the construction of new or alteration of stored knowledge structures in long-term memory (Van Merriënboer et al., 2006). According to Schnotz and Kürschner (2007), what qualifies an imposed load as GCL is the conscious construction of knowledge that requires additional cognitive capacity beyond the requirements of the task performance. A learning task unavoidably imposes more or less ICL and ECL, which do not necessarily result in learning, but occupy extra cognitive capacity. If cognitive activities do not go beyond task performance or result in learning, GCL would not be different from ICL and ECL.

Schnotz and Kürschner (2007) asserted that task performance and learning are fundamentally different processes; despite the fact that they are closely correlated, they operate on different sources of mental representations. Task performance operates on the representation of novel information in working memory, whereas learning operates on the representation of prior knowledge in long-term memory. Working memory is, therefore, not the place where learning occurs. "What does take place in working memory is information processing as part of the learning task performance (such as, for example, comprehending texts, solving equations, or proving theorems), which trigger with some likelihood changes in long- 
term memory" (p. 492). However, the suggested difference between task performance and learning to distinguish between ICL, ECL, and GCL needs further evidence.

\section{How to Distinguish between Intrinsic, Extraneous, and Germane Cognitive Load}

Moreno and Mayer (2007) posited that GCL and ICL occur in the same way, in which less experienced learners start selecting, organising, and integrating words and images with existing knowledge structures. They hereby engage in "essential processing" and "generative processing" to learn. The former refers to mentally selecting new information, while the latter refers to mentally organising novel information into coherent schemata and integrating with prior ones. Thus, like GCL, ICL is contributory to learning (De Jong, 2010).

Kalyuga (2011) suggested considering GCL as equal to ICL, and stated that GCL is not based on specific empirical evidence, whereas ICL is. According to Sweller (2010), GCL can be used to emphasise the amount of working memory resources that learners devote to dealing with ICL. Thus, the present formulation of cognitive load only consists of additive ICL and ECL rather than ICL, ECL, and GCL. Hence, a direct measurement should be developed to differentiate between only the two (Kalyuga, 2011; Sweller, 2010).

A traditional way to distinguish between the two types of load is to consider levels of prior domain-specific knowledge of learners. In other words, the effectiveness of an instructional design to manipulate ICL and ECL varies according to the expertise levels (i.e., the expertise reversal effect), implying that "instructional techniques that are highly effective with inexperienced learners can lose their effectiveness and even have negative consequences when used with more experienced learners" (Kalyuga, Ayres, Chandler, \& Sweller, 2003, p. 23). For instance, a spatially integrated design that provides necessary information for less experienced learners to learn better may contain unnecessary information that is intelligible in isolation for more experienced learners, thereby yielding extraneous load and interfere with their cognitive-task performance (Kalyuga, 2007). In such cases, high 


\section{Kuldas et al - The Use of Working Memory}

expertise learners inevitably hold mental representations of redundant information (i.e., representational holding process), thereby wasting their time and available cognitive capacity (Moreno \& Mayer, 2007). Thus, an instructional design that takes the expertise reversal effect into account would allow learners of all expertise levels to devote their cognitive resources to the construction of schemata.

\section{The Construction and Automation of Schemata}

"Whereas there are severe capacity limits to the amount of information from sensory memory that working memory can process, there are no known limits to the amount of information from long-term memory that can be processed by working memory" (Sweller, 2004, p. 13). This limitation of working memory is hereby less likely to impede processing various elements of information that are organised into coherent schemata, which are already structured, encoded, classified, and rehearsed information codes with common features in long-term memory (Van Merriënboer \& Sweller, 2005). Therefore, as Sweller et al. (1998) suggested, an instructional design should be aimed at facilitating conscious/mental combinations of visual and verbal instructional messages of a cognitive task into related schemata, which can later become automated as repeatedly and successfully being applied to the task.

"As is the case for schema construction, automation can free working memory capacity for other activities because an automated schema directly steers behaviour, without the need to be consciously processed in working memory" (Van Merriënboer \& Sweller, 2005, p. 6). Therefore, once schemata have been automated, learners will exert very little conscious effort to operate them (Van Gog, Ericsson, Rikers, \& Paas, 2005). With the help of automated schemata (unconscious processing), "human cognitive architecture handles complex material that appears to exceed the capacity of working memory" (Paas et al., 2003, p. 2).

An instructional intervention can facilitate the construction and automation of schemata as long as it is aligned with the expertise level. Otherwise the learning would be impeded, such as by asking low expertise learners to imagine the content of worked-out examples (Kalyuga, 2007). A way of 
helping the learners is to present them with spatially combined rather than segregated instructional messages, but this combination may have little or no contribution for more expert learners (Kalyuga et al., 2003). Leung, Low, and Sweller (1997) reported that supplementing a mathematical equation with an elaborated text did not improve the learning for learners who had sufficient knowledge because the equation was intelligible to them. As learners increase the knowledge necessary for a learning task, the advantages of integrating verbal explanations with visual illustrations disappear. In this stage, they learn better through only visual presentations (Leahy, Chandler, \& Sweller, 2003). The visual rather than verbal processing facilitates the construction of mental representations, thereby easing the construction and automation of schemata for learners at all levels of expertise (Kalyuga, 2012).

An instructional design that presents different modes of the same information (e.g., an animation and its textual explanation) over both visual and auditory modalities is less likely to impose high load as compared to only visual modality. Such a design can be beneficial for low expertise learners, who can learn better from the visual mode accompanied by a corresponding explanation as narration rather than as written text (Moreno \& Mayer, 2007). The presentation of static visual materials simultaneously with corresponding textual or oral explanations in a conventional learning environment (Sweller et al., 1998), while replacing the written explanation (on-screen text) with spoken text to describe the dynamic visual material in a multimedia learning environment can reduce high cognitive load, facilitate imagining the content of instruction (Tindall-Ford \& Sweller, 2006), and minimise the split-attention effect (Kalyuga, 2012; Moreno \& Mayer, 2007). Such advantages of spoken text over written text can disappear when (a) an auditory instruction contains longer segments (Leahy \& Sweller, 2011); (b) a narration is without its pictorial presentation; (c) a pictorial presentation is too unintelligible or is too intelligibly simple, not needing the narration; and (d) when spoken and written texts are concurrently presented (Kalyuga, 2012).

As a result, these suggestions for schema construction also emphasise how automated conscious knowledge facilitates working memory performance. Given that the automated schemata helps the conscious processing of novel information, conscious learning happens partially 


\section{Kuldas et al - The Use of Working Memory}

unconsciously. As such, how can one distinguish between conscious and unconscious learning? The following sections serve to clarify this question and also explain how working memory performance is facilitated or inhibited by unconscious learning processes (i.e., encoding, storage, and retrieval information mostly without deliberate and controlled attention and largely inaccessible to verbal report).

\section{Unconscious Learning Processes}

Cognitive load theory claims validity for conscious construction of the kinds of knowledge, such as reading, writing, and arithmetic, which have to be explicitly taught (Schnotz \& Kürschner, 2007). However, as Paas et al. (2003) highlighted, working memory, in which all conscious cognitive processing occurs, can handle only two or three novel interacting elements. "This number is far below the number of interacting elements that occurs in most substantive areas of human intellectual activity" (p. 2).

The human cognitive system is capable of storing more information in long-term memory through its unconscious channel than the conscious (Lewicki, Czyzewska, \& Hoffman, 1987). The unconscious system is structurally and functionally much more sophisticated than the conscious (Bargh \& Morsella, 2008). Lewicki et al. (1987) remarked that the unconscious system "releases the controlled processing from the responsibility of dealing with numerous tasks supporting every act of consciously controlled cognition" (p. 529), such as speech production, recognising shapes and locations of objects in three-dimensional space, or forming first impressions of a social stimulus. Furthermore, unconsciously learned information automatically primes appropriate responses to relevant stimuli, thereby operating on more information than could be operated consciously. This function is a general property of the human cognitive system (Lewicki et al., 1987).

Therefore, as Schnotz and Kürschner (2007) suggested, conscious processing should not be reckoned as the only prerequisite for learning. A growing body of literature suggests that the acquisition and application of knowledge is not solely a consciously goal-directed cognitive process; it is not merely subject to conscious awareness, conscious effort, conscious 
control, or consciously acquired knowledge (Kuldas, Bakar, \& Ismail, 2012). Extant studies (Bargh, Gollwitzer, Lee-Chai, Barndollar, \& Trötschel, 2001; Custers \& Aarts, 2010; Scott \& Dienes, 2010) suggest that learners can unconsciously form, retain, recall, and apply a goal-directed activity (e.g., decision-making) and create the same outcome as can be done consciously. This is because, as Bargh and Morsella (2008) acknowledged, an unconscious goal-directed process is not less deliberate, controlling, and adaptive than the conscious one.

Knowledge can be unconscious in the sense that learners are neither aware of how they acquire and learn it, nor aware of how the unconsciously acquired knowledge facilitates their cognitive-task performance (Lewicki et al., 1987). Dienes and Berry (1997) concluded from their review that learners can unconsciously learn to perform well in a task when their attention is focused on specific items and not on the underlying rules. For example, before having formal education, most learners have already unconscious knowledge about how to speak and how to listen without explicit instruction on semantic and syntactic rules of their first language. Such knowledge, referred to as biologically primary knowledge, lays foundations for the construction of biologically secondary knowledge, such as learning how to write and to read (Geary, 2002). The former is procedural, mostly acquired unintentionally and not easily verbalised, unlike the latter, which is declarative, intentional and easily expressible. Dienes and Berry (1997) further stressed that that knowledge used for task performance can be regarded as inaccessible to conscious introspection or to conscious awareness only in the sense that learners are unable to articulate freely how and what they learn. Thus, asking learners to articulate how they acquired and applied knowledge, and whether or not they intentionally used it for task demands, can be of the ways to determine whether the knowledge is conscious and unconscious.

Empirical evidence indicates that knowledge construction takes place mostly in unconscious perceptual (sensory information-processing), cognitive (e.g., associative memory networks), and emotional functions, which can later be accessible to conscious awareness (Kuldas et al., 2013). However, whether unconscious information processing is primarily an emotional, perceptual, or cognitive phenomenon is a highly controversial 


\section{Kuldas et al - The Use of Working Memory}

issue (Kihlstrom, Barnhardt, \& Tataryn, 1992). This controversy might be a reason for referring to unconscious processing under various terms, such as automatic, experiential, implicit, intuitive, adoptive unconscious, heuristic, associative, psychological, or non-conscious (Kuldas et al., 2013). Another reference to associative networks of neural activities of the brain is made; the activities form associations within and between information patterns at the outset of information processing, and subsequently, affect their retrieval processes (Sohn et al., 2005). A further reference to perceptual informationprocessing is made, suggesting an unconscious perceptual defence, unconsciously suppressing or even blocking sensory information that is undesirable (Erdelyi, 1974). The suppression of information may also be due to the limited capacity of visual-sensory processing, which does not allow for encoding multiple visual information simultaneously and consciously, and therefore, has to unconsciously suppress some of the messages to encode those messages that can be represented in the conscious mind (Kastner \& Ungerleider, 2000).

However these various references to unconscious processing are made (i.e., as automatic, experiential, implicit, intuitive, adoptive, heuristic, associative, psychological, nonconscious, perceptual defence, or suppression), the consensus is that the bulk of perceptual, cognitive, and emotional processing, including their interconnections, is inaccessible to conscious awareness and thus to verbal report (Kuldas et al., 2014a). A convincing reason for the distinctive references may be that the unconscious perceptual, cognitive, emotional and motivational functions cannot be easily referred to a single heading (i.e., the unconscious mind); instead, the term "unconscious processes" may be used (Westen, 1998). The unconscious processes can be either inhibitory or facilitatory to learners' conscious thoughts and acts in a classroom setting. An association between conscious and unconscious processing (e.g., forming and retrieving thoughts) is of elementary associative learning processes. A conscious goal-directed activity is accompanied with unconscious associative "memory networks", such as beliefs, wishes, desires, and thoughts, which are linked with "unconscious procedures", such as emotions, motives, and defences (Westen, 1998). These unconscious networks and procedures guide human behaviour by activating associated memories and affecting emotional states, flows of thoughts, and 
behavioural tendencies (Kuldas et al., 2013). This activation brings the emotional and motivational influence of past experiences into present experiences (Schacter, 1992; Westen, 1998). Activated expectations, desires, or fears motivate or demotivate learners investing the necessary cognitive effort (i.e., facilitating or inhibiting conscious learning processes).

\section{The Effect of Unconscious Emotional Processing on the Use of Working Memory}

"Affect acts as the on/off switch to motivation, which is the process by which goal-directed behavior is initiated and sustained either consciously or unconsciously" (Moreno, 2010, p. 137). Affect/motivation determines how learners perceive a cognitive learning task in terms of the amount of cognitive effort needed to deal with it (Schnotz \& Kürschner, 2007). However, most parts of the affective/motivational processes can be formed and activated unconsciously, thus, resulting in the unconscious evaluation of perceived information and unconscious behaviour (Bargh \& Morsella, 2008).

Through the limited conscious capacity, learners cannot promptly interfere with the preliminary unconscious evaluation of emotional experiences, with the unconscious influence concerning how they perceive information, acquire memories, feel, think, behave, and learn (Bargh \& Morsella, 2008). Experiencing intense negative emotions, such as panic, insecurity, or anxiety, and related thoughts (e.g., feeling incompetent) can inhibit effective learning, whereas other negative emotions, such as mild anxiety, and positive emotions, such as curiosity, can facilitate learning activities (Kuyper, Van Der Werf, \& Lubber, 2000). Due to the preliminary evaluation, humans unconsciously tend to approach emotionally desirable experiences that interfere with conscious processing (Epstein, 1994).

Although learners can later become aware of and evaluate their unconsciously initiated behaviour, this conscious evaluation does not mean that they are fully aware of emotional/motivational influences, such as urges, desires, or fears, nor does it indicate that they have complete conscious knowledge of why they are doing what they are doing. They can still be unaware the causal origins of their behaviour, of the behaviour itself, and of the influence of such behaviour on their positive and negative evaluations 


\section{Kuldas et al-The Use of Working Memory}

(Gawronski, Hofmann, \& Wilbur, 2006). Feelings, impressions, or prior beliefs can still unconsciously influence a typical cognitive task, such as reasoning and problem solving (Evans, 2003). Such factors can be uncontrollable; an unwanted thought can easily exceed one's conscious control and influence one's behaviour, such as, inhibiting learning and performance of a problem-solving task or mediating inferences and giving rise to inaccurate judgements or decisions (Efklides, 2006). Given such inhibitory effects, working memory seems to be occupied with emotional cognitive load (i.e., thoughts related or evoked by negative emotions). As such, further research is needed to provide insight into how the emotional load is related to the intrinsic and extraneous load.

As a result, the unconscious emotional/motivational processing can precede the arrival of its counterpart and determine the amount of cognitive effort to invest in a learning task. Hence, only focusing on the conscious processing capacity can deprive both educators and learners of the contribution of unconscious processing. Disregarding the affective/motivational processing limits the understanding of how human learning occurs. However, the question of how an effective educational implication of unconscious learning processes can be designed has yet to be tested (Kuldas et al., 2013). Such a test requires differentiating between conscious and unconscious motivation for cognitive resource expenditure, so as to explain how an instructional intervention must be tailored to meet learners' needs for motivation. As Sweller et al. (2011) emphasised, better learning (schema construction) depends on whether or not an instructional intervention stimulates learners to consciously allocate the necessary cognitive effort. An instructional design must allow students to be consciously aware of their motives and thus to avoid the inhibitory effects of unconscious emotional processing (i.e., engaging in thoughts or retrieving past experiences associated with negative emotional states). 


\section{Tailoring an Instructional Intervention to Learners' needs for Motivation}

Schnotz (2010) remarked that an instructional manipulation alone is not stimulating enough for the allocation of the necessary cognitive effort. To encourage learners of all expertise levels to exert the effort, an instructional guidance, aid, or design should be tailored not just to suit learner expertise level, but also to meet their motivational needs (Schnotz \& Kürschner, 2007), such as the need for an optimal challenge level of task difficulty. If learners perceive a learning task as too difficult or too easy, they are discouraged to persist to learn (Paas et al., 2005). For instance, when low expertise learners are provided with a multimedia presentation of a cognitive task without onscreen text, they perceive the task as complicated and frustrating and thus reduce persistence in dealing with it (i.e., low motivation for the use of available capacity in working memory); in contrast, relatively experienced learners consider the task challenging (i.e., high motivation for the use of capacity), thereby investing more cognitive effort and increasing their persistency (Schnotz, Fries, \& Horz, 2009).

To encourage low expertise learners to devote the effort to germane learning processes, such as engaging in learning a complex mathematical optimisation algorithm, Paas et al. (2005) suggested presenting an animation and its textual explanation onscreen to describe the learning task, but the difficulty level should be challenging. An unchallenging task is inhibitory (i.e., generating low motivation) rather than facilitatory to learning. In Schnotz and Rasch's (2005) study, animated pictures impaired the learning processes of low expertise learners because the animation made the task too easy (i.e., decreased the motivation, thereby decreasing cognitive effort expenditure). Low expertise learners spent less cognitive effort to learn from the animation. Nevertheless, the learners performed their task (learning date/time differences and the earth's rotation around its axis) better with the help of animated rather than static pictures. Thus, as predicted, low expertise learners usually invest less cognitive effort to learn via animation generating low motivation (Cooper, Tindall-Ford, Chandler, \& Sweller, 2001).

In addition, instead of making a learning task easier, educators should decrease their support and allow learners to learn or perform the task on their 


\section{Kuldas et al - The Use of Working Memory}

own (Schnotz \& Kürschner, 2007). In a series of studies (Kalyuga, Chandler, \& Sweller, 2001; Kalyuga, Chandler, Tuovinen, \& Sweller, 2001), learners with low expertise were allowed to practice worked-out examples and thereafter perform a difficult task; they hereby learned from the examples and performed the task better (i.e., high motivation leading to the investment of more cognitive effort). In contrast, high expertise learners were allowed to explore the same task on their own; they hereby learned most from the exploration and performed the task better than after practising the examples. Cooper et al. (2001) demonstrated that cognitive-task performance was facilitated by allowing low expertise learners to understand and remember the task related procedures and concepts through worked-out examples, while encouraging high expertise learners to do so on their own by imagining, referred to as the imagination effect. Leahy and Sweller (2005) reported that low expertise students' learning of a procedure (learning to use a bus timetable) was facilitated through worked-examples rather than imagination, however, this result reversed when their expertise increased.

To both high and low expertise learners, worked-out examples can be substantially beneficial, if they are stimulated to give explanations (i.e., the self-explanation effect) about what steps are needed to solve a problem and to establish a rationale for the problem-solving steps. In particular, stimulating high expertise learners to deliberately engage in learning-practice activities can improve their learning performance, referred to as the deliberate practice effect (Van Gog et al., 2005). However, Renkl (1997) argued that merely studying the worked-examples does not suffice to promote schema construction because it does not assure learners of avoiding misunderstanding. Furthermore, learners are not always able to identify how the examples are relevant to corresponding learning tasks or how to use the same problemsolving steps to deal with new problems. A rather different stance is taken by Schnotz and colleagues (2009), who argued that the examples are not motivational enough, even perceived as dull and unchallenging. To clarify the reasons for the different effects of worked-out examples on low and high expertise learners, Moreno (2006) stressed the need for further explanation on the relationship between motivational factors and the allocation of the necessary cognitive effort. 
IJEP - International Journal of Educational Psychology 4(2) 159

\section{The Relation of Motivational Factors with the Allocation of Cognitive Effort}

A commonly accepted view about human learning is that learners do not spontaneously engage in germane learning processes. The cognitive engagement is encouraged or discouraged by motivational factors, such as anxiety, probability of success, interest, and challenge, that activate, energise, and direct human behaviour (Kuldas et al., 2014b). Motivational factors, particularly goals, interests, and beliefs of learners determine whether or not they devote the necessary cognitive effort. For instance, unlike learners with low interest, those with high interest in a learning task would increase their cognitive effort to deal with the task (Hidi \& Renninger, 2006). Paas et al. (2005) reported that when the motivation was lower, less cognitive effort was invested, thus indicating lower cognitive performance; but when the motivation was higher, more cognitive resources were invested, resulting in higher cognitive performance.

Learner interest level is increased or decreased by their belief in their own competence to complete tasks (Moreno \& Mayer 2007). If learners do not believe they can perform a cognitive task successfully, they would not invest the necessary cognitive effort (Weiner, 2000). In contrast, they would invest the effort if they believe they can, and would, thus, perform better than those with low or no belief in their success (Wigfield \& Eccles, 2000).

Learners' interests can vary according to their achievement goals, such as: (a) "mastery-approach goal" to improve learning or attain competence in a learning task; (b) "mastery-avoidance goal" in order not to fall short of task mastery (avoiding skill decline, loss of existing knowledge, or learning failures); (c) "performance-approach goal" to outperform others or demonstrate competence; and (d) "performance-avoidance goal" in order not to appear incompetent or not to do worse than others (Elliot \& Thrash, 2001). When the goal is to increase competence on a task, learners devote greater effort to learn. On the contrary, they devote less cognitive effort, if the goal is solely to demonstrate task competence (Ford, Smith, Weissbein, Gully, \& Salas, 1998).

The amount of cognitive resource investment is a waste or necessity for an achievement goal, depending on learners' evaluation of costs of time and 


\section{Kuldas et al - The Use of Working Memory}

cognitive effort (Kuldas et al., 2014b). Learners would invest more cognitive resource if they believe it is necessary (Paas et al., 2005). Yet, as Schnotz (2010) highlighted, the evaluation process itself draws on motivational resources by taking some time and cognitive effort. Hence, an achievement goal is likely to draw upon motivational rather than cognitive resources.

Accordingly, the actual amount of motivational resources spent is the other determinant of cognitive effort expenditure for better learning and task performance. Only motivated learners devote the available capacity to the additional cognitive processing that is germane to learning (Schnotz et al., 2009). "When learners lack motivation they may fail to engage in generative processing even when cognitive capacity is available" (Moreno \& Mayer, 2007, p. 315).

However, the failure or impaired performance may also be the source rather than the result of investment decline (Roets \& Van Hiel, 2011b). Roets, Van Hiel, and Kruglanski (2013) showed that the unavailable or depleted cognitive capacity activates aversive feelings, which, in turn, substantially decrease motivation for task performance (i.e., indicating the causal effect of depleted cognitive capacity on motivation). Learners can maintain task performance, particularly under situational stressors (e.g., time pressure or noise), as long as they adequately have both motivation and cognitive capacity (Roets \& Van Hiel, 2011b). These findings indicate that when both motivation and cognitive capacity are low, learners may engage in unconscious processing of task-irrelevant information; conversely, when both are high, learners attend to task-relevant information. As for when motivation for processing additional information is high but available cognitive capacity is low, learning can be inhibited rather than facilitated, because the inadequate capacity does not allow learners to properly perceive even task-relevant information as useful for learning and task performance (Kuldas et al., 2014b). Hence, an instructional intervention must be aimed at the optimisation of both cognitive load and the exertion of cognitive effort (i.e., optimising the interaction between motivation and cognitive capacity).

The abovementioned findings substantiate the "Integrative Process Approach" proposed by Roets and Van Hiel (2011a). This approach provides new insights into the dynamic interplay between learners' affect, motivation, and cognitive capacity, which are "the most proximal process 
variables directly affecting information processing" (Roets \& Van Hiel, 2011a, p. 510). This dynamic/causal interplay determines both qualitative and quantitative values of information processing. To show how the interaction between cognitive capacity, affect, and motivation could be optimised (i.e., increasing motivation as long as cognitive capacity is available or adequate for deliberate processing task-related information), further research could apply the integrative process approach to instructional interventions.

\section{Conclusion}

This review has reconsidered the main concern of Cognitive Load Theory over the issue of how to optimise learners' use of working memory capacity. The review has aimed at explicating the need to investigate the role of unconscious processes, including emotional/motivational factors, in learning and performance of a cognitive task. The reviewed literature suggests that the use of working memory is determined not only by learners' expertise levels, but also by their emotional/motivational states. An instructional format would encourage learners to use the available capacity to perform and learn their task better, provided that the design is aligned with the emotional/motivational factors. This alignment would help educators predict whether providing learners with more or less information facilitates rather than inhibits learning. Educators also need further clarification on how an instructional design can be aligned with learners' motivational factors, to stimulate them to use their cognitive capacity for better learning.

The theory claims validity for the conscious construction of knowledge, the kinds of learning requiring conscious effort to take place in long-term memory. Traditionally, the theory does not concern itself with the unconscious construction of knowledge or the unconscious influence of motivational factors. The theory thereby deprives both learners and educators of what the unconscious processing can contribute to the learning and teaching activities, and whether it impedes or facilitates cognitive learning and task performance. This review suggests that the theory can be more effectively applied to instructional designs, provided that it takes the unconscious nature of human cognitive and emotional information- 


\section{Kuldas et al - The Use of Working Memory}

processing systems into account. The theory would thus predict what effects different emotional/motivational factors will have on the investment of cognitive effort. The framework of the cognitive load theory would be comprehensive with the integrative process approach to instructional designs, and thus, would provide new insights into the interaction between working memory capacity, affect, and motivation, in particular how this interaction could be optimised (i.e., increasing motivation under adequate cognitive capacity).

Further studies are needed to explain the relation between the investment of cognitive effort and the motivational factors to provide new insights into the following questions: (a) To what extent can learners consciously mediate their motivational factors (e.g., interest, beliefs, desires, or goals) to perform a cognitive learning task? (b) Do learners invest different amounts of cognitive effort in the task when they are consciously motivated and otherwise? (c) To what extent do learners' avoided thoughts (e.g., failure expectation) or undesirable experiences (e.g., past unsuccessful achievements) determine the investment of cognitive effort; for instance, whether or not learners' fear of failure highly affects the investment? Prospective studies could also provide more empirical evidence for whether or not the emotional load (i.e., taskirrelevant thoughts associated with negative emotions) is an additional cognitive load distinguished from the intrinsic and extraneous load.

\section{Acknowledgements}

The fist author gratefully acknowledges the support by the Institute of Postgraduate Studies, Universiti Sains Malaysia, under the USM PhD Fellowship Scheme.

\section{References}

Baddeley, A. (2012). Working memory: Theories, models, and controversies. Annual Review of Psychology, 63, 1-29. doi:10.1146/annurev-psych-120710-100422 
Bargh, J. A., \& Morsella, E. (2008). The unconscious mind. Perspectives on Psychological Science, 3, 73-79. doi:10.1111/j.17456916.2008.00064.x

Bargh, J. A., Gollwitzer, P. M., Lee-Chai, A., Barndollar, K., \& Trötschel, R. (2001). The automated will: Nonconscious activation and pursuit of behavioral goals. Journal of Personality and Social Psychology, 81, 1014-1027. doi:10.1037/0022-3514.81.6.1014

Chi, M. T. H. (2005). Common sense conceptions of emergent processes: Why some misconceptions are robust. Journal of the Learning Sciences, 14, 161-199. doi:10.1207/s15327809j1s1402_1

Cooper, G., Tindall-Ford, S., Chandler, P., \& Sweller, J. (2001). Learning by imagining. Learning of Experimental Psychology: Applied, 7, 68-82. doi:10.1037/1076-898X.7.1.68

Cowan, N. (2001). The magical number 4 in short-term memory: A reconsideration of mental storage capacity. Behavioral and Brain Sciences, 24, 87-114. doi:10.1017/S0140525X01003922

Custers, R., \& Aarts, H. (2010). The unconscious will: How the pursuit of goals operates outside of conscious awareness. Science, 329, 47-50. doi:10.1126/science. 1188595

De Jong, T. (2010). Cognitive load theory, educational research, and instructional design: Some food for thought. Instructional Science, 38, 105-134. doi:10.1007/s11251-009-9110-0

Dienes, Z., \& Berry, D. (1997). Implicit learning: Below the subjective threshold. Psychonomic Bulletin \& Review, 4, 3-23. doi: $10.3758 / \mathrm{BF} 03210769$

Efklides, A. (2006). Metacognition and affect: What can metacognitive experiences tell us about the learning process? Educational Research Review, 1, 3-14. doi:10.1016/j.edurev.2005.11.001

Elliot, A. J., \& Thrash, T. M. (2001). Achievement goals and the hierarchical model of achievement motivation. Educational Psychology Review, 13, 139-156. doi:10.1023/A:1009057102306

Epstein, S. (1994). Integration of the cognitive and the psychodynamic unconscious. American Psychologist, 49, 709-724. doi:10.1037/0003-066X.49.8.709 
Erdelyi, M. H. (1974). A new look at the new look: Perceptual defense and vigilance. Psychological Review, 81(1), 1-25. doi: $10.1037 / \mathrm{h} 0035852$

Evans, J. St. B. T. (2003). In two minds: Dual-process accounts of reasoning. Trends in Cognitive Sciences, 7, 454-459. doi:10.1016/j.tics.2003.08.012

Ford, J. K., Smith, E. M., Weissbein, D. A., Gully, S. M., \& Salas, E. (1998). Relationships of goal orientation, metacognitive activity, and practice strategies with learning outcomes and transfer. Journal of Applied Psychology, 83, 218-233. doi:10.1037/0021-9010.83.2.218

Gawronski, B., Hofmann, W., \& Wilbur, C. J. (2006). Are "implicit" attitudes unconscious? Consciousness and Cognition, 15, 485-499. doi.org/10.1016/j.concog.2005.11.007

Geary, D. C. (2000). Principles of evolutionary educational psychology.

Learning and Individual Differences, 12, 317-345. doi:10.1016/S1041-6080(02)00046-8

Gerjets, P., Scheiter, K., \& Catrambone, R. (2006). Can learning from molar and modular worked examples be enhanced by providing instructional explanations and prompting self-explanations?

Learning and Instruction, 16, 104-121. doi:10.1016/j.learninstruc.2006.02.007

Hidi, S., \& Renninger, K. A. (2006). A four-phase model of interest development. Educational Psychologist, 41, 111-127. doi:10.1207/s15326985ep4102_4

Kalyuga, S. (2007). Expertise reversal effect and its implications for learnertailored instruction. Educational Psychology Review, 19, 509-539. doi:10.1007/s10648-007-9054-3

Kalyuga, S. (2011). Cognitive load theory: How many types of load does it really need? Educational Psychology Review, 23, 1-19. doi:10.1007/s10648-010-9150-7

Kalyuga, S. (2012). Instructional benefits of spoken words: A review of cognitive load factors. Educational Research Review, 7, 145-159. doi:10.1016/j.edurev.2011.12.002 
Kalyuga, S., Ayres, P., Chandler, P., \& Sweller, J. (2003). The expertise reversal effect. Educational Psychologist, 38, 23-31. doi:10.1207/S15326985EP3801_4

Kalyuga, S., Chandler, P., \& Sweller, J. (2001). Learner experience and efficiency of instructional guidance. Educational Psychology, 21, 523. doi:10.1080/01443410124681

Kalyuga, S., Chandler, P., Tuovinen, J., \& Sweller, J. (2001). When problem solving is superior to studying worked examples. Journal of Educational Psychology, 93, 579-588. doi:10.1037/00220663.93.3.579

Kastner, S., \& Ungerleider, L. G. (2000). Mechanisms of visual attention in the human cortex. Annual Review of Neuroscience, 23, 315-341. doi:10.1146/annurev.neuro.23.1.315

Kihlstrom, J. F., Barnhardt, T. M., \& Tataryn, D. J. (1992). The psychological unconscious: Found, lost, and regained. American Psychologist, 47, 788-791.

Kuldas, S., Bakar, A. Z., \& Ismail, H. N. (2012). The role of unconscious information processing in the acquisition and learning of instructional messages. Electronic Journal of Research in Educational Psychology, 10, 907-940.

Kuldas, S., Hashim, S. B., Ismail, H. N., Samsudin, M. A., \& Bakar, A. Z. (2014a). The unconscious allocation of cognitive resources to taskrelevant and task-irrelevant thoughts. Australian Journal of Educational \& Developmental Psychology, 14, 1-16.

Kuldas, S., Ismail, H. N., Hashim, S., \& Bakar, Z. A. (2013). Unconscious learning processes: Mental integration of verbal and pictorial instructional materials. SpringerPlus, 2, 105. doi:10.1186/21931801-2-105

Kuldas, S., Satyen, L., Ismail, H. N., \& Hashim, S. (2014b). Greater cognitive effort for better learning: Tailoring an instructional design for learners with different levels of knowledge and motivation. Psychologica Belgica, 54, 350-373. doi:doi.org/10.5334/pb.aw

Kuyper, H., Van Der Werf, M. P. C., \& Lubbers, M. J. (2000). Motivation, metacognition, and self-regulation as predictors of long-term 
educational attainment. Educational Research and Evaluation, 6, 181-206. doi:10.1076/1380-3611(200009)6:3;1-A;FT181

Leahy, W., Chandler, P., \& Sweller, J. (2003). When auditory presentations should and should not be a component of multimedia instruction. Applied Cognitive Psychology, 17, 401-418. doi:10.1002/acp.877

Leahy, W., \& Sweller, J. (2005). Interactions among the imagination, expertise reversal, and element interactivity effects. Journal of Experimental Psychology: Applied, 11, 266-276. doi:10.1037/1076898X.11.4.266

Leahy, W., \& Sweller, J. (2011). Cognitive load theory, modality of presentation and the transient information effect. Applied Cognitive Psychology, 25, 943-951. doi:10.1002/acp.1787

Leung, M., Low, R., \& Sweller, J. (1997). Learning from equations or words. Instructional Science, 25, 37-70.

doi:10.1023/A:1002969618881

Lewicki, P., Czyzewska, M., \& Hoffman, H. (1987). Unconscious acquisition of complex procedural knowledge. Journal of Experimental Psychology: Learning, Memory, and Cognition, 13, 523-530. doi:10.1037/0278-7393.13.4.523

Moreno, R. (2006). When worked examples don't work: Is cognitive load theory at an Impasse? Learning and Instruction, 16, 170-181. doi:10.1016/j.learninstruc.2006.02.006

Moreno, R. (2010). Cognitive load theory: More food for thought. Instructional Science, 38, 135-141. doi:10.1007/s11251-009-9122-9

Moreno, R., \& Mayer, R. E. (2007). Interactive multimodal learning environments. Educational Psychology Review, 19, 309-326. doi:10.1007/s10648-007-9047-2

Paas, F., Renkl, A., \& Sweller, J. (2003). Cognitive load theory and instructional design: Recent developments. Educational Psychologist, 38, 1-4. doi:10.1207/S15326985EP3801_1

Paas, F., Tuovinen, J. E., Van Merriënboer, J. J. G., \& Darabi, A. A. (2005). A motivational perspective on the relation between mental effort and performance: Optimizing learner involvement in instruction. Educational Technology Research and Development, 53, 25-34. doi:10.1007/BF02504795 
Pollock, E., Chandler, P., \& Sweller, J. (2002). Assimilating complex information. Learning and Instruction, 12, 61-86. doi:10.1016/S0959-4752(01)00016-0

Renkl, A. (1997). Learning from worked-out examples: A study on individual differences. Cognitive Science, 12, 1-29. doi:10.1016/S0364-0213(99)80017-2

Roets, A., \& Van Hiel, A. (2011a). An integrative process approach on judgment and decision making: The impact of arousal, affect, motivation, and cognitive ability. The Psychological Record, 61, 497-520. Retrieved from http://opensiuc.lib.siu.edu/tpr/vol61/iss3/11

Roets, A., \& Van Hiel, A. (2011b). Impaired performance as a source of reduced energy investment in judgement under stressors. Journal of Cognitive Psychology, 23, 625-632. doi:10.1080/20445911.2011.550569

Roets, A., Van Hiel, A., \& Kruglanski, A. W. (2013). When motivation backfires: Optimal levels of motivation as a function of cognitive capacity in information relevance perception and social judgment. Motivation and Emotion, 37, 261-273. doi:10.1007/s11031-0129299-0

Schacter, D. L. (1992). Understanding implicit memory: A cognitive neuroscience approach. American Psychologist, 47, 559-569. doi:10.1037/0003-066X.47.4.559

Schnotz, W. (2010). Reanalyzing the expertise reversal effect. Instructional Science, 38, 315-323. doi:10.1007/s11251-009-9104-y

Schnotz, W., \& Kürschner, C. (2007). A reconsideration of cognitive load theory. Educational Psychology Review, 19, 469-508. doi:10.1007/s10648-007-9053-4

Schnotz, W., \& Rasch, T. (2005). Enabling, facilitating, and inhibiting effects of animations in multimedia learning: Why reduction of cognitive load can have negative results on learning. Educational Technology Research and Development, 53, 47-58. doi:10.1007/BF02504797

Schnotz, W., Fries, S., \& Horz, H. (2009). Motivational aspects of cognitive load theory. In M. Wosnitza, S. A. Karabenick, A. Efklides, \& P. 
Nenniger (Eds.), Contemporary motivation research: From global to local perspectives (pp. 69-96). New York: Hogrefe \& Huber.

Scott, R. B., \& Dienes, Z. (2010). Knowledge applied to new domains: The unconscious succeeds where the conscious fails. Consciousness and Cognition, 19, 391-398. doi:10.1016/j.concog.2009.11.009

Sohn, M. H., Goode. A., Stenger, V. A., Jung, K. J., Carter, C. S., \& Anderson, J. R. (2005). An information-processing model of three cortical regions: Evidence in episodic memory retrieval. NeuroImage, 25, 21-33. doi:10.1016/j.neuroimage.2004.11.001

Sweller, J. (2004). Instructional design consequences of an analogy between evolution by natural selection and human cognitive architecture. Instructional Science, 32, 9-31. doi:10.1023/B:TRUC.0000021808.72598.4d

Sweller, J. (2010). Element interactivity and intrinsic, extraneous, and germane cognitive load. Educational Psychology Review, 22, 123138. doi:10.1007/s10648-010-9128-5

Sweller, J., Ayres, P., \& Kalyuga, S. (2011). Cognitive load theory. New York: Springer.

Sweller, J., Van Merriënboer, J., \& Paas, F. (1998). Cognitive architecture and instructional design. Educational Psychology Review, 10, 251296. doi:10.1023/A:1022193728205

Tindall-Ford, S., \& Sweller, J. (2006). Altering the modality of instructions to facilitate imagination: Interactions between the modality and imagination effects. Instructional Science, 34, 343-365. doi:10.1007/s11251-005-6075-5

Van Gog, T., Ericsson, K. A., Rikers, R. M. J. P., \& Paas, F. (2005). Instructional design for advanced learners: Establishing connections between the theoretical frameworks of cognitive load and deliberate practice. Educational Technology Research and Development, 53, 73-81. doi:10.1007/BF02504799

Van Merriënboer, J. J. G., \& Sweller, J. (2005). Cognitive load theory and complex learning: Recent developments and future directions.

Educational Psychology Review, 17, 147-177. doi:10.1007/s10648-005-3951-0 
Van Merriënboer, J. J. G., Kester, L., \& Paas, F. (2006). Teaching complex rather than simple tasks: Balancing intrinsic and germane load to enhance transfer of learning. Applied Cognitive Psychology, 20, 343352. doi:10.1002/acp. 1250

Van Merriënboer, J. J. G., Kirschner, P. A., \& Kester, L. (2003). Taking the load off a learner's mind: Instructional design for complex learning. Educational Psychologist, 38, 5-13.

doi:10.1207/S15326985EP3801_2

Weiner, B. (2000). Interpersonal and intrapersonal theories of motivation from an attributional perspective. Educational Psychology Review, 12, 1-14. doi:10.1023/A:1009017532121

Westen, D. (1998). The scientific legacy of Sigmund Freud: Toward a psychodynamically informed psychological science. Psychological Bulletin, 124, 333-371. doi:10.1037/0033-2909.124.3.333

Wigfield, A., \& Eccles, J. S. (2000). Expectancy-value theory of achievement motivation. Contemporary Educational Psychology, 25, 68-81. doi:10.1006/ceps.1999.1015

Seffetullah Kuldas is a PhD student in the School of Educational Studies at Universiti Sains Malaysia.

Shahabuddin Hashim is a Senior Lecturer in the School of Educational Studies at Universiti Sains Malaysia.

Hairul Nizam Ismail is an Associate Professor in the School of Educational Studies at Universiti Sains Malaysia.

Zainudin Abu Bakar is a Senior Lecturer in the Faculty of Education at Universiti Teknologi Malaysia.

Contact Address: Seffetullah Kuldas. School of Educational Studies, Universiti Sains Malaysia, 11800 USM, Penang, Malaysia. E-mail: seffetu@gmail.com 